\title{
AVALIAÇÃO DO USO DE FERRAMENTA DE EDUCAÇÃO A DISTÂNCIA PARA TREINAMENTO EM RADIOLOGIA E DIAGNÓSTICO POR IMAGEM
}

\author{
PÁDUA, Rodrigo Donizete Santana de ${ }^{1}$ \\ PINHEIRO, Marília Guimarães ${ }^{2}$ \\ ELIAS-JUNIOR, Jorge ${ }^{3}$
}

Recebido em: 2008-07-31

Aprovado em: 2008-09-19

ISSUE DOI: $10.3738 / 1982.2278 .128$

RESUMO: Este trabalho apresenta um estudo sobre a viabilidade do uso de ferramenta para ambiente de Educação a Distância (EaD) no apoio ao treinamento de estudantes em Radiologia e Diagnóstico por Imagens. Os testes foram realizados com o Moodle, que possui licença livre e código aberto, com base em imagens de exames reais, previamente diagnosticados e incorporados ao ambiente EaD. Através desse ambiente, os alunos são convidados a testar sua capacidade de descrever achados e possíveis diagnósticos a partir de testes envolvendo questões de múltipla escolha e de verdadeiro/falso. Foi desenvolvido um conjunto de testes pilotos para treinamento de diagnóstico de lesão focal de fígado. Foram necessárias adaptações para a incorporação de imagens no ambiente analisado.

Palavras-chave: Educação a distância. Educação em medicina. Ensino apoiado por computador.

SUMMARY: This paper presents a computational feature environment to support the training and evaluation of medical students in radiology and diagnostic images by using E-learning. It used the Moodle, which is a free and open source software, with adjustments for viewing medical images. Tests on images of actual examinations, previously diagnosed and incorporated into the e-learning environment Moodle, let students assess their ability to make findings and possible diagnoses. The performance of the student is registered for evaluation. Some types of focal lesion of liver were used like pilots cases. Adjustments were necessary to incorporate images of the environment analysis.

Keywords: E-learning. medical education. Computer-assisted instruction (CAI).

\footnotetext{
${ }^{1}$ Especialista em Tecnologias de Informação e Comunicação, Bacharel em Ciência Da Computação, UNICOC, Ribeirão Preto. Pesquisador e desenvolvedor pela empresa Innolution Sistemas de Informática Ltda. rodrigo_dsp@yahoo.com.br

${ }^{2}$ Mestre em Ciência da Computação pelo ICMC-USP, São Carlos. Doutoranda pela Faculdade de Medicina de Ribeirão Preto da USP. mariliapinheiro@ gmail.com

${ }^{3}$ Docente da Faculdade de Medicina de Ribeirão Preto da USP. jejunior@fmrp.usp.br
} 


\section{INTRODUÇÃO}

A Educação a Distância (EaD) constitui-se uma modalidade de ensino já bem antiga, porém, é nos últimos tempos que tem adquirido maior força e mais respeito perante a

sociedade em geral. A maior parte desse sucesso deve-se, talvez, ao impulso dado pelas novas tecnologias de informação e comunicação (TIC), que com a combinação das tecnologias eletrônicas e de telecomunicações, têm possibilitado a difusão da informação em diversas partes do mundo em questão de segundos.

Os chamados ambientes digitais de aprendizagem, através da combinação de diversas mídias, como textos, sons, imagens e vídeos, se não substituem por completo a tradicional modalidade de ensino presencial em sala de aula, ao menos agregam recursos que transformam as atividades de ensino e aprendizagem em uma experiência lúdica mais completa. Além disso, esses ambientes oferecem ferramentas de comunicação síncrona e assíncrona, o que garante uma interação professor-aluno e aluno-aluno algumas vezes até mais interessantes do que no ensino tradicional.

Um campo que tem se beneficiado bastante desse novo modelo de $\mathrm{EaD}$ é o das Ciências da Saúde, em particular a Medicina. São áreas que estão em constante e veloz desenvolvimento científico e tecnológico, e em que a qualidade do serviço prestado pode ter grande importância na qualidade de vida do cliente. Logo, verifica-se uma necessidade de atualização constante dos profissionais dessa área, que muitas vezes dispõem de pouco tempo ou moram/trabalham distantes de instituições de ensino que seguem os moldes tradicionais de ensino.

Este trabalho tem o objetivo de demonstrar a investigação e configuração de um ambiente digital de aprendizagem, neste caso o Moodle, para a criação e disponibilização de Quizzes On line onde estudantes de medicina e médicos residentes poderão treinar e autoavaliar seus conhecimentos no diagnóstico clínico de patologias através da análise de imagens médicas radiológicas e reposta a testes de múltipla escolha e verdadeiro/falso. O estudo piloto terá por base dois estudos de caso para diagnóstico de lesão focal de fígado (SEMELKA et al apud HO; KRANSDORF; REINHOLD, 2006).

A inspiração para apresentação dos casos aos estudantes foi o Portal AuntMinnie.com e o Serviço Case of the $\mathrm{Day}^{4}$, portal na web que contém diversos recursos e

4 http://www.auntminnie.com 
informações para interessados na área de Radiologia e Diagnóstico por Imagem, além de um Quiz On Line onde estudantes e médicos podem aprimorar seus conhecimentos.

$\mathrm{O}$ ambiente digital de aprendizagem Moodle foi estudado a fundo, com vistas a identificar recursos que sejam úteis à criação do Quiz On Line. Foi feito levantamento de requisitos para o desenvolvimento e implementação da proposta.

Para resultados satisfatórios, além do cadastramento dos questionários no Moodle, foram necessárias adaptações especialmente em função da necessidade de se trabalhar com imagens.

Espera-se que este trabalho contribua com novas idéias que favoreçam programas de educação e reciclagem de médicos radiologistas, bem como o ensino e treinamento em Radiologia e Diagnóstico por Imagem para estudantes de medicina e interessados de outras áreas.

\section{A EDUCAÇÃO A DISTÂNCIA E AS CIÊNCIAS DA SAÚDE}

Educação a Distância é o nome que se dá à modalidade de ensino na qual não há a necessidade do aluno estar fisicamente presente em um ambiente formal de ensinoaprendizagem. Outra característica encontrada na $\mathrm{EaD}$ é a possibilidade de separação temporal entre professor e aluno, ou seja, a interação entre ambos não acontece necessariamente em tempo real. Para que a $\mathrm{EaD}$ seja viável, diversos meios de comunicação podem ser utilizados para a interconexão entre professor e aluno, como correio, mídias televisiva e radiofônica e, mais recentemente e em maior escala, a Internet.

A EaD não é uma modalidade de ensino recente, sendo existente em forma embrionária e empírica já no século XIX. É possível dividi-la em três gerações distintas:

- Primeira geração: ensino por correspondência, caracterizado principalmente pelo envio de material impresso que deve ser utilizado pelos alunos para estudo. Exemplos de cursos nesta modalidade são oferecidos até hoje no Brasil por empresas como o Instituto Universal Brasileiro $^{5}$ e o Instituto Monitor ${ }^{6}$.

- Segunda geração: teleducação/telecursos, que utilizam mídias como rádio e televisão para transmissão de aulas expositivas. Nesta modalidade, a iniciativa mais conhecida do

5 http://www.institutouniversal.com.br/

6 http://www.institutomonitor.com.br/ 
público brasileiro é o Telecurso $2000^{7}$, programa televisivo produzido a partir de uma parceria entre a Fundação Roberto Marinho e o Sistema FIESP.

- Terceira geração: ambientes interativos, os quais permitem o acesso à informação em tempos diferentes, através das novas TIC, possibilitando uma melhor interação alunoaluno e professor-aluno. Cursos de graduação e pós-graduação lato sensu totalmente à distância ou semi-presenciais são exemplos cada vez mais recorrentes da utilização de ambientes interativos na educação. Vale a pena citarmos também o Sistema Universidade Aberta do Brasil (UAB) ${ }^{8}$, criado em 2005 pelo Ministério da Educação (MEC), que utiliza a $\mathrm{EaD}$ em uma parceria entre instituições de ensino superior, estados e municípios para expandir a oferta de cursos superiores públicos.

Entre as diversas contribuições que as TIC trouxeram à EaD, talvez a mais importante seja a possibilidade de criação e utilização dos chamados ambientes digitais de aprendizagem, sistemas computacionais que utilizam de recursos de tecnologia digital e telecomunicações para disponibilização de conteúdo e mediação de atividades de ensino e aprendizagem via Internet. Eles permitem a integração de diversas mídias (textos, imagens, vídeos, hipertextos), linguagens e recursos, além de permitir a interação entre pessoas a qualquer tempo (ALMEIDA, 2003).

Atualmente há diversos desses ambientes disponíveis para uso, alguns oferecidos por empresas e com custo para obtenção, manutenção e suporte, e outros disponíveis para download gratuito na Internet. Alguns dos gratuitos mais conhecidos são:

- Moodle ${ }^{9}$ : distribuído gratuitamente sob a licença GNU General Public License $(\mathrm{GPL})^{10}$, é desenvolvido de forma a atender alguns princípios defendidos por teorias de ensino-aprendizagem como, por exemplo, o Construtivismo e o Construcionismo (MOODLE, 2008).

- TelEduc $^{11}$ : idealizado e desenvolvido por pesquisadores do Núcleo de Informática Aplicada à Educação (Nied) da Universidade Estadual de Campinas (Unicamp), esse ambiente é distribuído sob a licença GPL e foi concebido tendo como foco o aprendizado

7 http://www.telecurso2000.org.br/

8 http://uab.capes.gov.br/

9 http://moodle.org/

10 Licença de software que permite a sua livre distribuição e redistribuição, além do livre acesso ao seu códigofonte, seja para estudo ou modificação. Mais informações podem ser obtidas na página oficial do projeto: http://www.gnu.org/licenses/gpl.html

11 http://www.teleduc.org.br/ 
a partir da resolução de problemas e da comunicação intensa entre os participantes do curso (ROCHA apud MORAES, 2002).

- TIDIA-AE ${ }^{12}$ : projeto pertencente ao programa Tecnologia da Informação no Desenvolvimento da Internet Avançada (TIDIA), financiado pela Fundação de Amparo à Pesquisa do Estado de São Paulo (FAPESP), o TIDIA-AE (o AE é abreviatura de Aprendizado Eletrônico) reúne os esforços de pesquisadores de várias instituições de ensino do estado de São Paulo para o desenvolvimento de um ambiente de colaboração e ferramentas de suporte e apoio ao ensino e aprendizagem (TIDIA-AE, 2008).

Os ambientes digitais de aprendizagem não se restringem apenas às atividades de EaD puramente on line, podendo ser utilizados em cursos semi-presenciais, nos quais o aluno realiza uma parte dos estudos à distância e outra parte em aulas presenciais, além de servirem também como ferramenta de apoio em atividades de cursos totalmente presenciais (CRISTANTE et al., 2003).

As Ciências da Saúde constituem um campo em constante e rápido desenvolvimento, dada a velocidade com que surgem avanços científicos e tecnológicos no mundo atual. Portanto, é necessário que os profissionais de suas diferentes áreas estejam sempre bem atualizados em relação às inovações de sua área de conhecimento, para que possam proporcionar um atendimento de qualidade e com segurança aos seus pacientes/clientes.

Entretanto, muitos desses profissionais enfrentam dificuldades para conseguir participar de cursos, palestras ou eventos científicos, devido à falta de tempo livre, ou mesmo à inexistência de um horário fixo de trabalho, o que por vezes inviabiliza a sua participação em qualquer curso no molde presencial tradicional. Outro fator que atrapalha é a não existência de instituições de ensino ou cursos na localidade em que o profissional reside e/ou trabalha.

Nesse ponto, as TIC e a EaD podem ter grande importância, seja no oferecimento de cursos de pós-graduação lato sensu, seja em cursos de atualização ou em programas de educação continuada. Uma iniciativa que não pode deixar de ser citada é a da Universidade Federal de São Paulo (UNIFESP), que mantém o portal UNIFESP Virtual ${ }^{13}$, onde são oferecidos cursos, seminários, guias de auto-estudo, simulados, entre outros, para estudantes e profissionais da área da Saúde.

12 http://tidia-ae.incubadora.fapesp.br/portal 13 http://www.virtual.unifesp.br/home/info.php 
No caso da área médica, a EaD ganhou uma nova denominação: Educação Médica à Distância (EMaD). Este termo é utilizado, por exemplo, no artigo de Christante et al. (2003), no qual os autores fazem uma análise crítica das contribuições da EMaD na Educação Médica Continuada. Segundo os autores, o Brasil possui inúmeros centros de excelência em ensino e pesquisa na área médica, porém a maioria destes está localizada nas regiões Sul e Sudeste. A EMaD, portanto, pode ser um meio de levar essa excelência aos diversos cantos do país, propiciando através da Educação Médica Continuada, melhorias em alguns aspectos da prática médica.

Já na área de Enfermagem, a Universidad Nacional de Rosario, na Argentina, utilizou a EaD em seu curso de mestrado para oferecer a disciplina Economia e Administração de Serviços de Enfermagem. Essa experiência é relatada no trabalho de Cristante et al. (2003), professoras da Universidade Federal de Minas Gerais, que elaboraram e ministraram a disciplina. As autoras dividiram-na em três momentos diferentes: no primeiro, foi realizada uma videoconferência, tendo como objetivo apresentar a disciplina e explicar sua proposta metodológica; no segundo, atividades didáticas foram realizadas à distância com a utilização de dois módulos; por fim, o terceiro momento foi caracterizado por um encontro presencial, quando houve a interação face a face dos sujeitos do processo ensinoaprendizagem. Segundo elas, a experiência mostrou que a $\mathrm{EaD}$ é uma ferramenta pedagógica eficaz e possível, que permite a qualificação de enfermeiros que têm dificuldades de acesso aos processos convencionais de pós-graduação.

Na Medicina, possivelmente é na especialidade de Radiologia e Diagnóstico por Imagem que estão concentradas a maioria das iniciativas de EMaD. Isto se deve talvez à forte relação que essa área tem com as tecnologias digitais, o que atrai cientistas da computação, engenheiros eletrônicos e pesquisadores de outras áreas correlatas a aplicar seus conhecimentos na resolução de problemas desta especialidade médica. Um exemplo disso é o WRAD, descrito por Pizzio; Silva; Beltran (2000/2001), que consiste em uma ferramenta para disponibilizar um banco de imagens radiológicas com patologias definidas e propiciar um ambiente de aulas virtuais na Internet. Embora tenha sido desenvolvido tendo como públicoalvo a comunidade médico-veterinária, não há nada que impeça sua utilização na área de Medicina humana.

Outra iniciativa interessante de desenvolvimento de ferramenta para apoiar a EMaD em Radiologia e Diagnóstico por Imagem é descrita no trabalho de Ângelo; Schiabel 
(2002). No trabalho, os autores descrevem a utilização de uma base de imagens mamográficas digitalizadas, associada a uma base de dados com os laudos fornecidos por radiologistas, para a criação de um esquema para ser utilizado no treinamento de avaliação diagnóstica em mamografia via Internet. Nesse esquema, um laudo é fornecido pelo usuário e, logo em seguida, o laudo dado pelo especialista é carregado da base de dados para comparação. Esta ferramenta proporciona então um canal por onde estudantes e ingressantes na área de análise de imagens mamográficas possam se aperfeiçoar.

\section{O Portal AuntMinnie.com e o serviço Case of the Day}

O AuntMinnie.com disponibiliza várias informações e recursos na área de Radiologia e Diagnóstico por Imagens para aqueles que desejam aprimorar seus conhecimentos e aptidões nessa área. O site começou a ser desenvolvido em 1999 e foi lançado em novembro do mesmo ano pelo seu fundador, o médico radiologista Phillip Berman (AUNTMINNIE, 2008).

Entre os recursos oferecidos pelo site, pode-se citar: notícias, artigos científicos, $e$ books ${ }^{14}$, fóruns de discussão, comunidades digitais, entre vários outros. Há também a AuntMinnieTV, que veicula reportagens e entrevistas em vídeo digital com especialistas da área.

Na seção Education ${ }^{15}$ do site, os destaques são o OnLineCMe ${ }^{16}$ e o Case of the Day. O OnLineCMe provê um mecanismo de obtenção de cursos on line para educação continuada de radiologistas, médicos assistentes, enfermeiros e outros profissionais da Saúde.

O Case of the Day é um serviço no qual radiologistas, médicos residentes, estudantes de medicina e demais interessados (esses atores serão aqui referenciados pelo termo "aluno") podem testar seus conhecimentos através da avaliação de casos clínicos da área de Radiologia.

No serviço, o caso de um determinado paciente é apresentado em várias páginas da web. As primeiras páginas apresentam imagens médicas do paciente, juntamente com questões relativas às imagens para serem respondidas pelo aluno. As páginas posteriores apresentam outras informações sobre o caso, como os Achados, o Diagnóstico Diferencial, o Diagnóstico, os Pontos Principais, as Referências utilizadas, entre outras, servindo para

14 Livros em formato digital.

15 Correspondente em inglês para "Educação".

16 Acrônimo para "On Line Continuing Medical Education", em português "Educação Médica Continuada On Line" 
proporcionar ao aluno um maior aprofundamento no estudo do caso. A última página traz apenas uma mensagem de Congratulações ao aluno por ter concluído o estudo do caso.

Nas páginas de questões de um caso clínico do Case of the Day são mostrados um ou mais thumbnails ${ }^{17}$ de imagens médicas (radiografia, tomografia computadorizada, ultrassonografia, entre outras) do paciente ao qual o caso clínico pertence (Figura 1). Com um clique de mouse sobre qualquer um dos thumbnails mostrados, o navegador web exibe outra página, na qual a imagem correspondente ao thumbnail clicado pode ser visualizada em tamanho maior (Figura 2). Na parte superior da página de exibição da imagem (Figura 2), há: um botão à esquerda que quando clicado exibe a imagem anterior à atual; um botão à direita que, quando clicado, exibe a imagem posterior à atual; e um link que, quando clicado, exibe de volta a página atual de questões sobre o caso clínico.

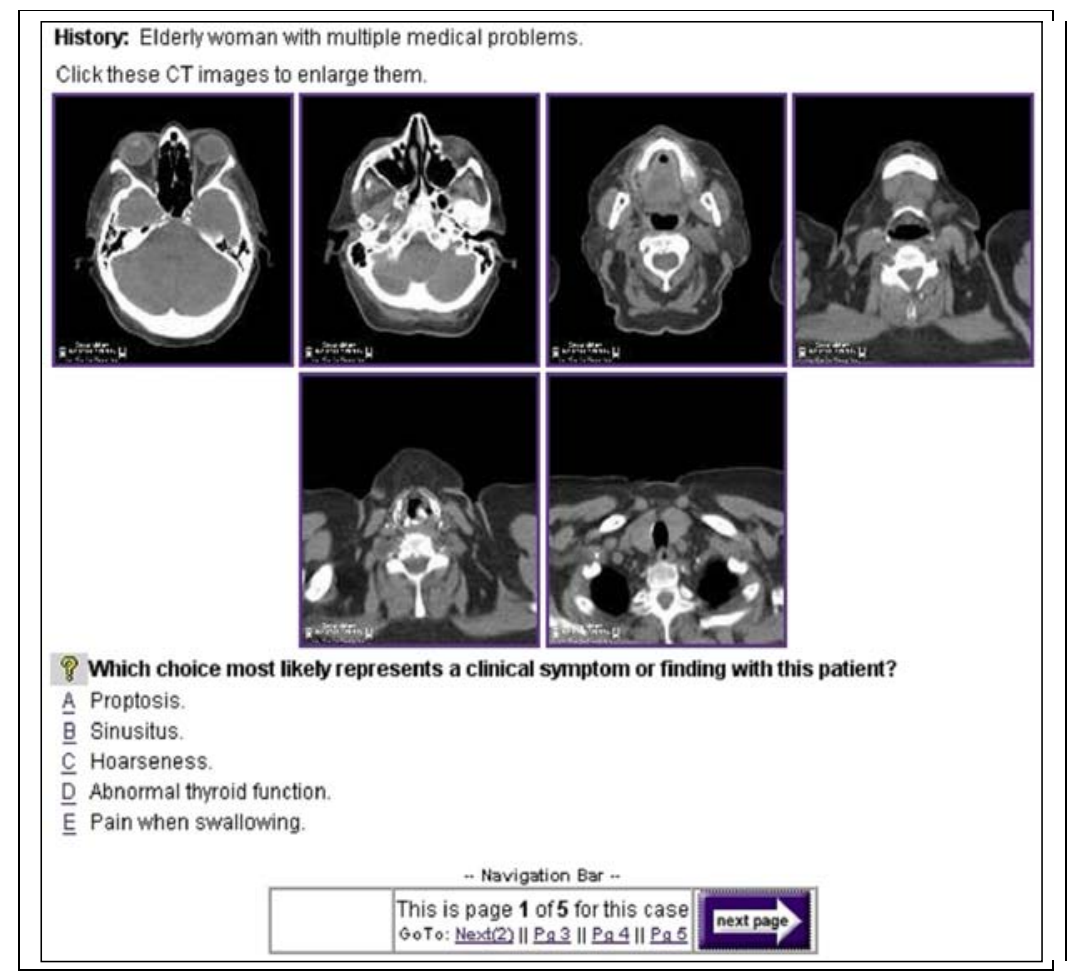

Figura 1. Recorte da Página de Questões de um Case of the Day, site AuntMinnie.com. 


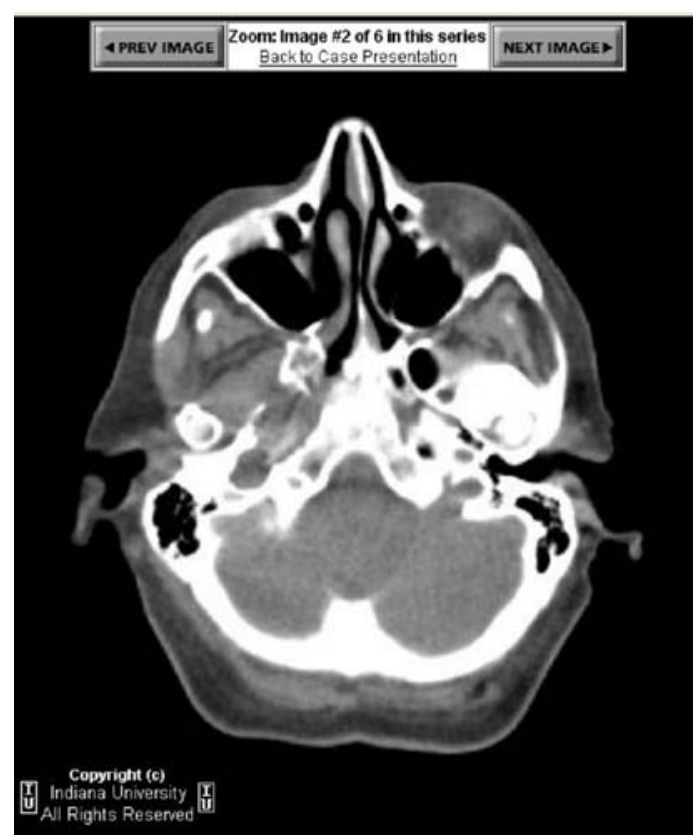

Figura 2. Recorte de uma página de exibição de imagem no Case of the Day.

De volta à página atual de questões (Figura 1), logo abaixo dos thumbnails é exibida uma questão de múltipla escolha (alternativas A, B, C, D e E) ou algumas afirmações com alternativas de verdadeiro ( $\mathrm{T}$, do correpondente em inglês true) ou falso (F, do correspondente em inglês false), para o aluno responder com base na avaliação das imagens apresentadas. A resposta é feita com um clique de mouse sobre a letra correspondente à alternativa desejada. A letra é um link que abre outra página onde o aluno é informado se sua resposta foi correta ou incorreta (Figura 3). Nesta mesma página (Figura 3), há um link que permite voltar à página atual de questões do caso, e outro link que abre uma outra página na qual é possível o aluno verificar o seu aproveitamento até o momento (Score). A página de Score (Figura 4) apresenta o número de questões respondidas, o número de acertos, o número de erros e o percentual de acertos, sendo computadas todas as respostas realizadas em todos os casos clínicos estudados desde o início da sessão (login), ficando esses valores armazenados até que o aluno encerre a sessão (logout) ou que a mesma expire. Na página do Score (Figura 4) também há um link que redireciona para a página atual de questões do caso clínico. 


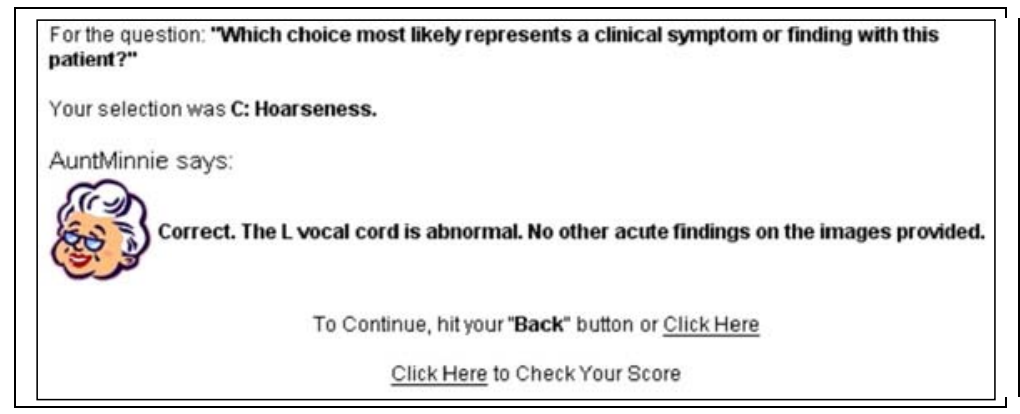

Figura 3. Recorte de uma página exibida logo após o clique em alternativa de questão apresentada em página de questões sobre o caso clínico no Case of the Day, informando que a resposta neste caso foi correta.

Em uma questão (Figura 1), sempre é possível escolher outra opção, porém apenas a primeira resposta é computada no Score.

\begin{tabular}{|l|r|}
\hline \multicolumn{3}{|c|}{ Here is Your Report Card! } \\
\hline Number of questions you have answered: & 1 \\
\hline Number of questions not counted (see below): & 0 \\
\hline Number of times CORRECT: & 1 \\
\hline Number of times INCORRECT: & 0 \\
\hline Your Score: & $100 \%$ \\
\hline $\begin{array}{l}\text { A note about scoring: Your score is based on your FIRST REPLY to any question during a browser } \\
\text { session. A "session" ends when you close your browser or when your connection to our site is idle for 30 } \\
\text { minutes or longer. Even if you answer a question wrong, you should continue to search for the right } \\
\text { answer because additional wrong answers will not be counted against you (and you will learn more). }\end{array}$ \\
Hit your "Back" button or Click Here to Return to Case Presentation
\end{tabular}

Figura 4. Recorte da página de Score, onde é possível o aluno verificar seu aproveitamento nos testes do Case of the Day.

As demais páginas de apresentação do caso clínico (posteriores às de questões) trazem apenas maiores informações textuais e/ou de imagens do caso, não havendo uma maior interação do aluno com o sistema, como ocorre nas páginas de questões.

Tanto na parte superior quanto na parte inferior de cada página de apresentação e de questões do caso, há uma barra de links e botões que permitem ao aluno navegar entre todas as páginas do caso clínico. Essa barra pode ser vista na parte inferior da Figura 1.

O Case of the Day constitui uma interessante ferramenta que provê um auxílio para que estudantes e profissionais da área de Radiologia possam fazer uma auto-avaliação e treinar seus conhecimentos na área ou mesmo adquirir novos conhecimentos. No entanto, através de uma avaliação do sistema no papel de aluno, foi possível identificar alguns pontos fracos ou a serem melhorados. 
Um ponto a se destacar é na exibição das imagens em tamanho maior. Quando algum dos thumbnails de imagens do caso é clicado, o navegador abre outra página, onde a imagem em tamanho maior será exibida, deixando de apresentar a página com as questões e demais thumbnails. Para voltar ao questionário, o aluno deve clicar em um link na página de exibição da imagem para abrir a de questões novamente, o que acaba se tornando uma dificuldade caso haja a necessidade de alternar várias vezes entre a visualização das imagens e das questões. Além disso, a operação do sistema pode se tornar confusa caso o aluno tenha pouca familiaridade com sistemas informatizados. Esse mesmo inconveniente é verificado na escolha de uma alternativa para uma questão, que quando escolhida redireciona para outra página que informa se a escolha foi correta ou incorreta, e na verificação do Score do aluno.

Outro ponto a ser destacado é sobre a escolha da alternativa para uma determinada questão. O sistema permite que o aluno responda às questões quantas vezes quiser. Apesar de ser mais uma decisão de projeto do que um erro e de ser computada no Score apenas a primeira resposta, tal método pode levar o aluno a descobrir a resposta correta para a questão através de tentativa-e-erro, ao invés de um raciocínio baseado em evidências contidas nas imagens analisadas por ele.

Também há de se destacar a maneira como é calculado o Score do aluno. O percentual de aproveitamento é calculado com base apenas no número de questões respondidas pelo aluno e no número de seus acertos, desconsiderando uma possível diferença de relevância ou nível de dificuldade entre as questões.

Uma possível melhoria do sistema diz respeito à exibição das imagens em tamanho maior para visualização pelo aluno. Ao invés de o aluno ser direcionado para outra página quando clica no thumbnail da imagem, uma nova janela do navegador ou mesmo uma janela pop-up ${ }^{18}$ poderia ser aberta para exibir a imagem em tamanho maior. Esse tipo de abordagem evita que o aluno se perca navegando em diversas páginas web, além de permitir que ele visualize a imagem e analise as questões e suas alternativas concomitantemente.

Com relação ao questionário, poderia haver uma caixa de seleção ao lado de cada uma das alternativas de cada questão, de forma que o aluno pudesse fornecer sua resposta selecionando a caixa correspondente à alternativa que acredita ser correta. A confirmação da resposta poderia ser feita apenas quando o aluno desse um clique de mouse sobre um botão ao lado da questão, ação esta que já retornaria logo abaixo dela uma mensagem informando se a resposta foi ou não correta. Em ambos os casos (correta ou incorreta), pode ser oferecido

18 Espécie de janela extra do navegador, mais comumente utilizada em sites para veiculação de propagandas. 
também ao aluno um feedback, com um pequeno texto explicativo sobre o porquê de ser correta ou incorreta.

Outra melhoria em relação ao questionário é a criação e utilização de um esquema em que se possa atribuir valores de relevância às questões, de acordo com seu nível de dificuldade, possibilitando, assim, um cálculo de Score baseado não apenas no número de erros e acertos.

\section{O AMBIENTE MOODLE}

O Moodle é um software de distribuição livre e código-fonte aberto que tem como objetivo propiciar um ambiente para a elaboração e oferecimento de cursos on line dentro de um conceito de aprendizagem colaborativa. O nome é um acrônimo para Modular ObjectOriented Dynamic Learning Environment, em português Ambiente de Aprendizado Dinâmico Modular Orientado a Objetos, que se refere tanto ao modo como o software foi desenvolvido quanto à maneira que um curso pode ser abordado (Autor, 2008).

O Moodle foi criado com o objetivo de promover uma educação sócioconstrucionista, que se baseia na elaboração de atividades, colaboração entre os integrantes do curso, reflexão crítica, entre outros. Para isso, o desenho e construção do sistema são apoiados em quatro conceitos principais:

- Construtivismo: teoria pedagógica elaborada por Jean Piaget que defende que a construção do conhecimento se dá pela interação do indivíduo com o ambiente. Toda nova informação recebida por uma pessoa é confrontada com seu conhecimento anterior, dando origem a um novo conhecimento.

- Construcionismo: essa teoria defende que a aprendizagem acontece de forma mais efetiva quando um novo conhecimento é utilizado para construir algo que outros possam experimentar. Como exemplo, se um indivíduo lê um texto e monta uma apresentação de slides com base no que leu para apresentar a um conjunto de pessoas, seu aprendizado será mais efetivo do que se tivesse somente lido o texto e não o utilizado para criar nada novo.

- Construcionismo Social: pode ser entendido como uma extensão dos conceitos anteriores. Aqui o conhecimento é construído de forma colaborativa, com os indivíduos de um grupo social construindo objetos uns para os outros, compartilhando significados.

- Comportamento Separado e Conectado: diz respeito à observação das motivações das pessoas em uma discussão. No comportamento separado, o sujeito tende a utilizar a lógica 
e a razão para encontrar falhas e incoerências nos argumentos de seu oponente. No comportamento conectado, há uma maior empatia e aceitação da subjetividade, levando o sujeito a ouvir e realizar perguntas para tentar entender o ponto de vista do outro. Em uma mescla das duas abordagens, a qual é chamada comportamento construído, o sujeito é capaz de escolher um dos dois comportamentos, de acordo com a situação em que se encontra.

Embasado nessas premissas, o Moodle possibilita um processo de ensinoaprendizagem centrado no aluno, saindo do modelo tradicional onde o professor é a fonte única de conhecimento. O professor adquire um papel de influenciador e moderador, enquanto os participantes do curso, ora assumem o papel de alunos, ora de professores (MOODLE, 2008).

O Moodle é composto de várias ferramentas (módulos) que permitem uma experiência de ensino-aprendizagem colaborativa. Dentre elas, o Questionário será focado neste estudo. Este módulo permite a criação de questionários que podem ser formados por questões de múltipla escolha, verdadeiro ou falso, dissertativas ou associativas, entre outras variações.

Esse módulo no Moodle permite definir vários parâmetros para configuração. Alguns desses parâmetros são: tempo que o questionário ficará disponível, número de questões que serão exibidas por página, número de tentativas que o aluno pode ter para responder às questões, entre outros. Há ainda a possibilidade de configuração de alguns parâmetros para as questões, como no caso da múltipla escolha, que pode ter uma única alternativa correta ou mais de uma. É possível utilizar uma mesma questão em mais de um questionário, sem a necessidade de refazê-la, apenas pela associação da questão cadastrada ao questionário que se deseja.

Para cada questão criada, independente de seu tipo, há a possibilidade de criação de feedbacks para o aluno. Por exemplo, para uma questão de verdadeiro ou falso, e supondo que a resposta correta seja "verdadeiro", pode-se associar um texto à alternativa "verdadeiro", explicando o porquê dessa ser a resposta correta, assim como pode-se também associar outro texto à alternativa "falso", explicando o porquê dessa ser a alternativa incorreta. Esses textos serão então apresentados ao aluno, de acordo com a alternativa que ele escolher. Dessa forma, proporciona-se uma experiência de aprendizagem mais completa, visto que o aluno aprende mais tanto com seus acertos quanto com seus erros, o que não seria possível com um questionário feito nos moldes tradicionais com tinta e papel.

No módulo de Questionários do Moodle, tanto os enunciados das questões quanto as alternativas (no caso de múltipla escolha) e os feedbacks, são elaborados em pequenos 
editores WYSIWYG ${ }^{19}$ internos, permitindo inserir facilmente diversos estilos e tamanhos de fontes, caracteres especiais, imagens e vários outros recursos. Na prática, o conteúdo editado é transformado em código $\mathrm{HTML}^{20}$, para que seja interpretado pelo navegador. Há um botão junto ao editor que permite alternar a visualização do conteúdo entre o modo que será exibido para o usuário (modo WYSIWYG) e o código HTML (modo TEXTO). A Figura 5 exibe um desses editores do módulo Questionário com um exemplo de enunciado, enquanto na Figura 6 é exbido o mesmo enunciado no modo HTML.

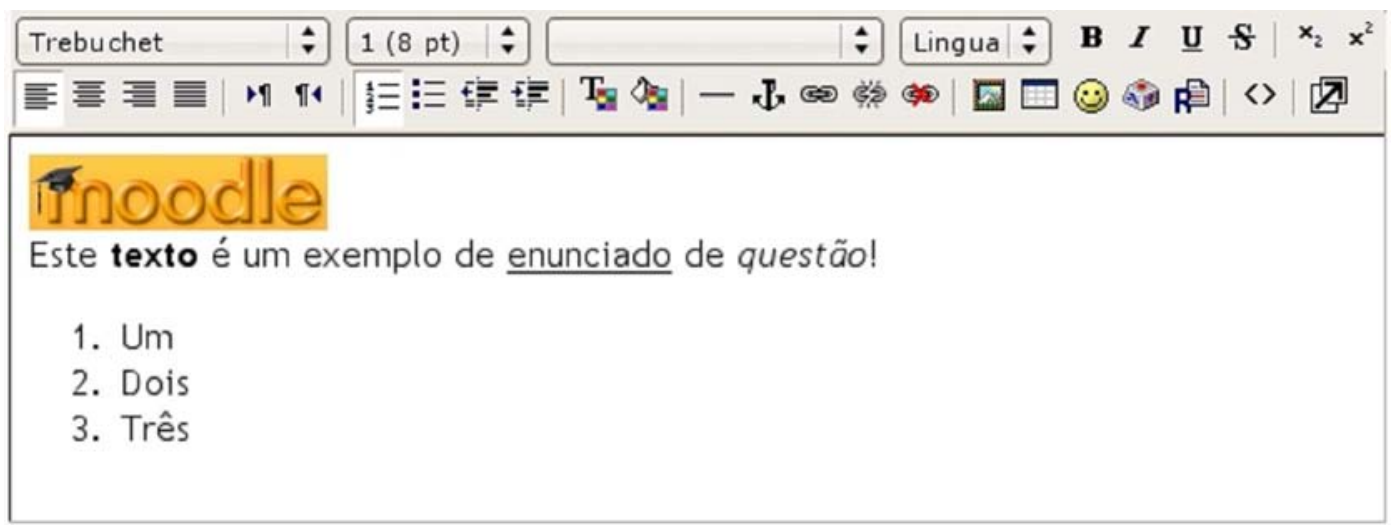

Figura 5. Editor de enunciado de questão do módulo Questionário no modo WYSIWYG.

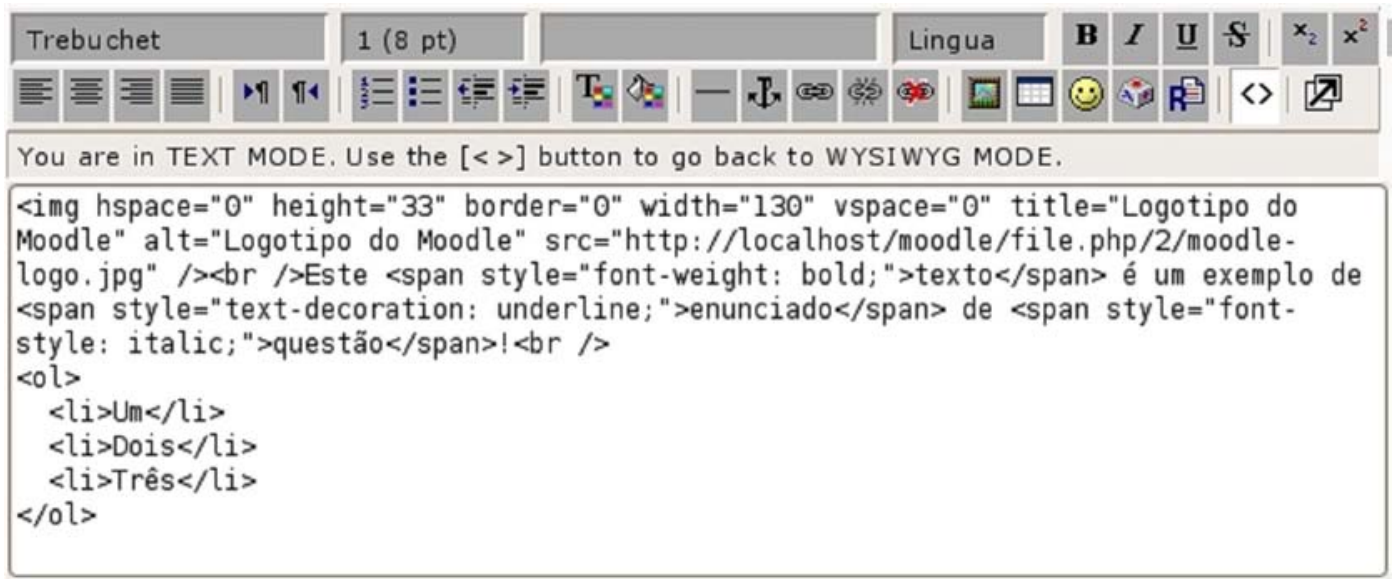

Figura 6. Editor de enunciado de questão do módulo Questionário no modo TEXTO.

\section{Elaboração do Quiz On Line}

19 Acrônimo de "What You See Is What You Get", em português "O que você vê é o que você tem". Diz respeito à característica de um aplicativo exibir na tela um documento que está sendo manipulado com a mesma aparência que terá em sua versão final de utilização (impresso ou página da web, por exemplo). Exemplos conhecidos deste tipo de aplicativos são os editores de texto Writer do pacote OpenOffice.org e o Word do pacote Microsoft Office.

20 Hypertext Markup Language, em português Linguagem de Marcação de Hipertexto, é utilizada para a criação de páginas web. 
Para a criação do Quiz, foi utilizado o sistema Ubuntu Linux ${ }^{21}$, versão 8.04 LTS. O Ubuntu é um sistema operacional baseado em Linux, distribuído gratuitamente e desenvolvido com o objetivo de ser de fácil instalação e utilização por qualquer pessoa. $\mathrm{O}$ Ubuntu conta com vários repositórios na Internet, onde são disponibilizados diversos softwares, também de código-fonte aberto e distribuição livre, para instalação em computadores com esse sistema operacional. O próprio Moodle está disponível nos repositórios do Ubuntu.

O Ubuntu possui ainda ferramentas para instalação e atualização de softwares, tanto em modo gráfico (e.g. Synaptic) quanto em modo texto (e.g. $A P T^{22}$ ). Essas ferramentas fazem a busca dos pacotes necessários nos repositórios e efetuam o seu download e instalação no computador local. Através da utilização do $A P T$, com apenas dois comandos foi possível instalar todos os softwares necessários para a criação do Quiz. O primeiro deles foi:

- sudo apt-get install apache2 mysql-server-4.1 php5 php5-mysql phpmyadmin com o qual foram instalados e integrados o servidor web Apache ${ }^{23}$ (versão 2), o sistema de gerenciamento de banco de dados $M y S Q L^{24}$ (versão 4.1), a linguagem de programação para web $P H P^{25}$ (versão 5) e a ferramenta para administração de bancos de dados em $M y S Q L$, chamada $p h p M y A_{d m i n}{ }^{26}$ (versão 2.11). Todos esses são pré-requisitos para a instalação do Moodle, exceto o phpMyAdmin, que apenas provê uma interface gráfica mais amigável com o usuário para a administração de bancos de dados.

O segundo comando utilizado foi:

- sudo apt-get install moodle moodle-book moodle-debian-edu-theme

que buscou nos repositórios do Ubuntu e instalou na máquina o ambiente Moodle e alguns outros módulos e temas. Algumas informações básicas de configuração são solicitadas ao usuário durante o processo de instalação, como senha do administrador etc.

Tendo por base o estudo do serviço Case of the Day do portal AuntMinnie.com, foi criado um conjunto de requisitos desejáveis para o sistema de Quiz On Line. Os requisitos foram pensados e elaborados de forma a manter algumas características julgadas positivas no Case of The Day e também a corrigir alguns pontos fracos do mesmo. O resultado é apresentado na Tabela 1.

21 http://www.ubuntu-br.org/

22 Acrônimo para "Advanced Packaging Tool", em português "Ferramenta de Empacotamento Avançada"

23 http://httpd.apache.org/

24 http://www.mysql.com/

25 http://www.php.net/

26 http://www.phpmyadmin.net/home page/index.php 
Tabela 1. Requisitos Funcionais de Software para Quiz On Line

(continua)

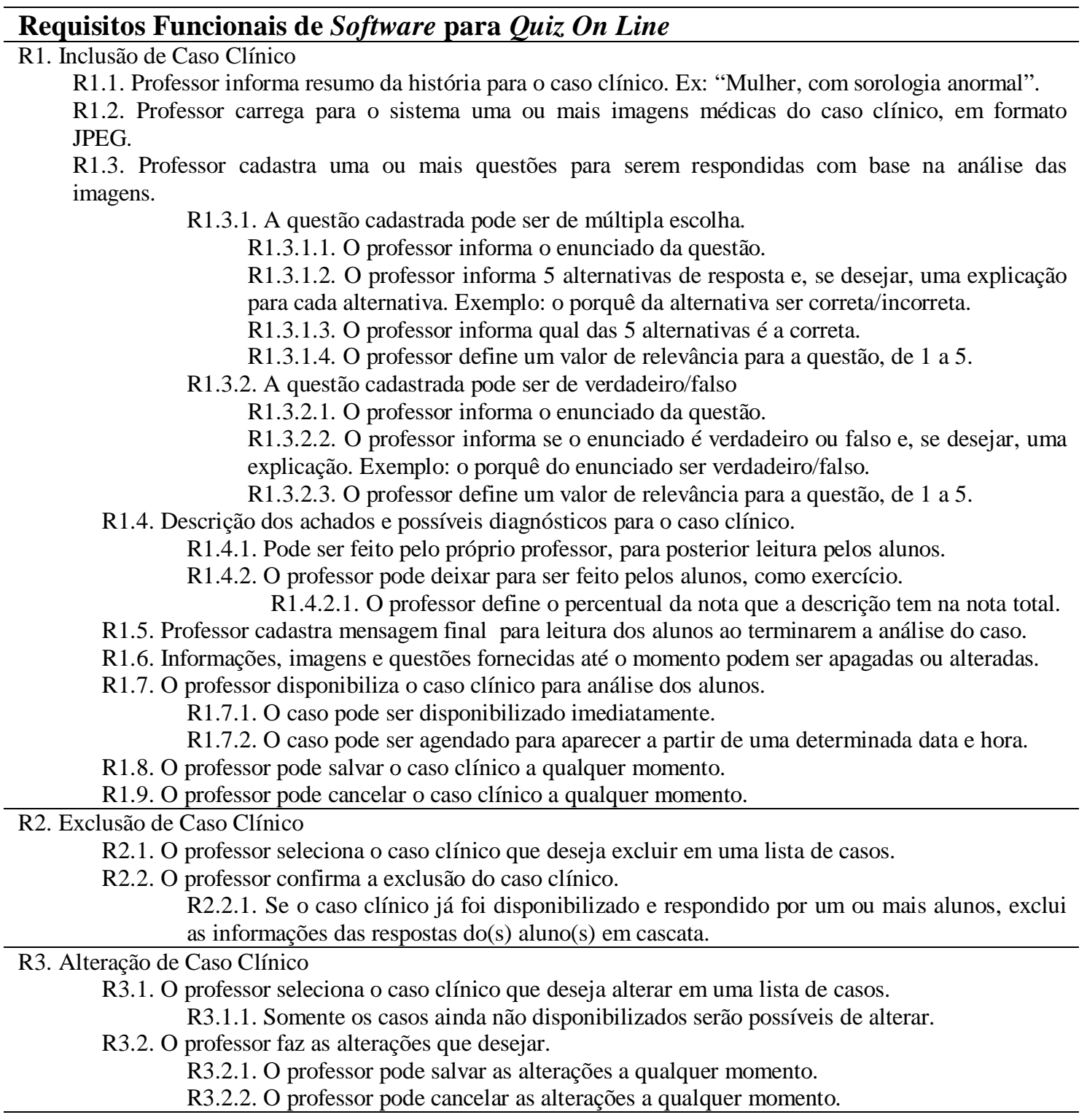


Tabela 1. Requisitos Funcionais de Software para Quiz On Line

(Conclusão)

\author{
R4. Estudo e Análise de Caso Clínico \\ R4.1. Aluno avalia as imagens. \\ R4.1.1. Um clique sobre um thumbnail abre a imagem em tamanho maior em pop-up.
}

R4.2. Aluno responde as questões.

R4.2.1. O aluno avalia a questão, seleciona uma alternativa e confirma.

R4.2.2. O aluno é informado se a resposta foi correta ou incorreta; comentário é exibido.

R4.2.3. O Score é atualizado com o número de questões respondidas, número de acertos, número de erros e percentual de aproveitamento (calculado com base no peso da questão).

R4.3. Descrição dos achados e possíveis diagnósticos para o caso.

R4.3.1. Se foi feito pelo professor, o aluno apenas lê para complemento de seu estudo.

R4.3.2.Se não foi feito pelo professor, o aluno escreve a descrição de acordo com sua interpretação e conhecimentos.

R4.4. O aluno pode sair a qualquer momento do caso e retornar posteriormente para o término.

$\mathrm{R} 4.5$. O aluno pode encerrar a análise do caso a qualquer momento.

R5. Verificação e Atribuição de Notas

R5.1. Professor seleciona o caso clínico em uma lista de casos disponibilizados.

R5.2. Professor seleciona o aluno numa lista entre os que já finalizaram o estudo e análise do caso.

R5.3. Se a descrição dos achados e possíveis diagnósticos foi feita pelo próprio professor.

R5.3.1. Apenas verifica a nota obtida nos testes.

R5.4. Se as descrição dos achados e possíveis diagnósticos foi deixada como exercício para os alunos

R5.4.1. Analisa descrição feita pelo aluno, atribui nota e, se desejar, comenta.

R5.4.2. Soma a nota dos testes e da descrição.

Com o estudo realizado sobre o Moodle, em particular do módulo Questionário, foi possível verificar que o ambiente disponibiliza diversos recursos para a criação do Quiz. Foram realizados testes mais funcionais, tendo por base imagens utilizadas por docentes da Faculdade de Medicina de Ribeirão Preto, com vistas a verificar a adequação do ambiente aos requisitos, identificando quais são e quais não são atendidos e ainda quais são atendidos parcialmente.

Foram elaborados dois questionários para estudos de caso. Esses dois questionários pilotos servem para o treinamento de diagnóstico de lesões focais de fígado, sendo um para o diagnóstico de Adenoma Hepático e outro para o diagnóstico de Carcinoma Hepatocelular (CHC). As informações sobre ambos os diagnósticos foram lançadas e organizadas no Moodle.

Foram feitas questões de múltipla escolha e verdadeiro/falso, cada uma com pesos diferentes na nota final e com mensagens de feedback ao aluno em cada uma das alternativas. Para ilustração, parte do questionário sobre Adenoma Hepático pode ser visto na Figura 7. 


\section{RESULTADOS}

Por ser o Moodle um ambiente de EaD de propósito genérico, este não possui em seu módulo de Questionários nenhuma ferramenta específica para a visualização e análise de imagens pelos alunos. Entretanto, na ferramenta "Criar nova pergunta" há uma opção "Descrição", que permite a criação de um enunciado combinando elementos textuais, tabelas, imagens, entre outros, através de um editor WYSIWYG. Utilizando essa opção, é possível inserir as imagens que deverão ser avaliadas pelos alunos.

Um problema encontrado nessa abordagem é o fato de as imagens serem exibidas na página com os seus tamanhos originais, o que pode ocupar um espaço muito grande na tela e dificultar a navegação do aluno.

Uma solução encontrada foi a criação de thumbnails das imagens, definindo novas dimensões de altura e largura para apresentação dessas através da ferramenta de inserção de figuras do próprio Moodle (Figura 8) e pode ser acionada através de um botão do editor WYSIWYG. Cada thumbnail é inserido e exibido dentro de uma célula de tabela criada com o auxílio do editor WYSIWYG, como pode ser visto na Figura 9.

Nucleus, v.5, n.2, out. 2008 
Quiz sobre Adenoma Hepático

Analise as imagens a seguir e responda às questões:
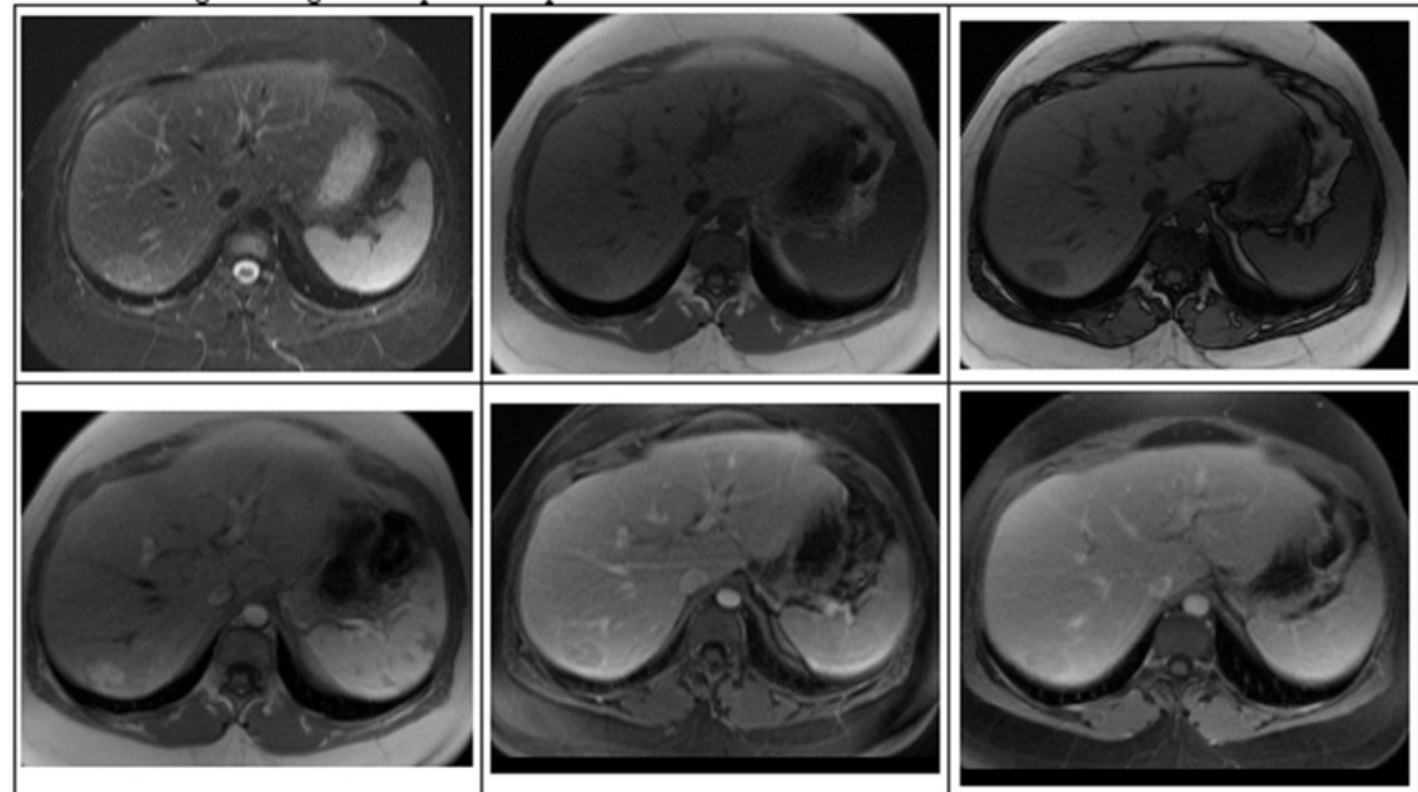

1. Com re lação aos limites, contomos e homogeneidade interna, pode-se dizer que são, respectivamente: [Peso: S] a) Bem definidos - Regulares - Homogêneo [Feedback: Parabéns, sua resposta está correta!]

b) Mal definidos - Regulares - Homogêneo [Feedback: Os contomos são regulares e a homogeneidade intema é homogênea, porém os limites não são mal definidos.]

c) Bem definidos - Imprecisos - Variável [Feedback: Os limites são bem definidos, porém os contonos não são imprecisos e a homogeneidade intema não é variável.]

d) Bem definidos - Regulares - Heterogêneo [Feedback: Os limites são bem definidos e os contomos são regulares, porém a homogeneidade intema não é heterogênea.]

e) Mal definidos - Imprecisos - Variável [Feedback. Todas as características estão incorretas.]

2. Sobre a intensidade de sinal T1 em-fase, fora-de-fase e com supressão de gordura, as imagens apresentam, respectivamente, quais caracteristicas? [Peso: 4]

a) Isointensa a discretamente hipointensa - perda de sinal - perda de sinal [Feedback: Parabéns, sua resposta está correta!]

b) Discretamente hịointensa - isointensa - isointensa [Feedback. Todas as caracteristicas estão incorretas.]

c) Isointensa - hipointensa - perda de sinal [Feedback. Com supressão de gordura há perda de sinal, porém em-fase não é isotensa e fora-de-fase não é hipointensa.]

d) Isointensa - perda de sinal - hịerintensa [Feedback. Fora-de-fase há perda de sinal, porém em fase não é isointensa, e com supressão de gordura não é hiperintensa.]

e) Discretamente hipointensa - hiperintensa - isointensa [Feedback: Todas as características estão incorretas.]

3. Na intensidade de sinal T2 ocorra com supressão de gordura haverá perda de sinal. A afinmativa é : [Peso: 2]

a) Verdadeira [Feedback. Parabéns, sua resposta está conreta!]

b) Falsa [Feedback: Haverá sim perda de sinal caso T2 ocorra com supressão de gordura.]

Observação: Por questão de conveniência, a resposta correta de cada questão foi colocada sempre na primeira opção. Não há motivos para se preocupar com a ordem das opções, pois o Moodle as embaralha a cada acesso feito por um aluno.

Figura 7. Exemplo de Quiz elaborado para Adenoma Hepático. 


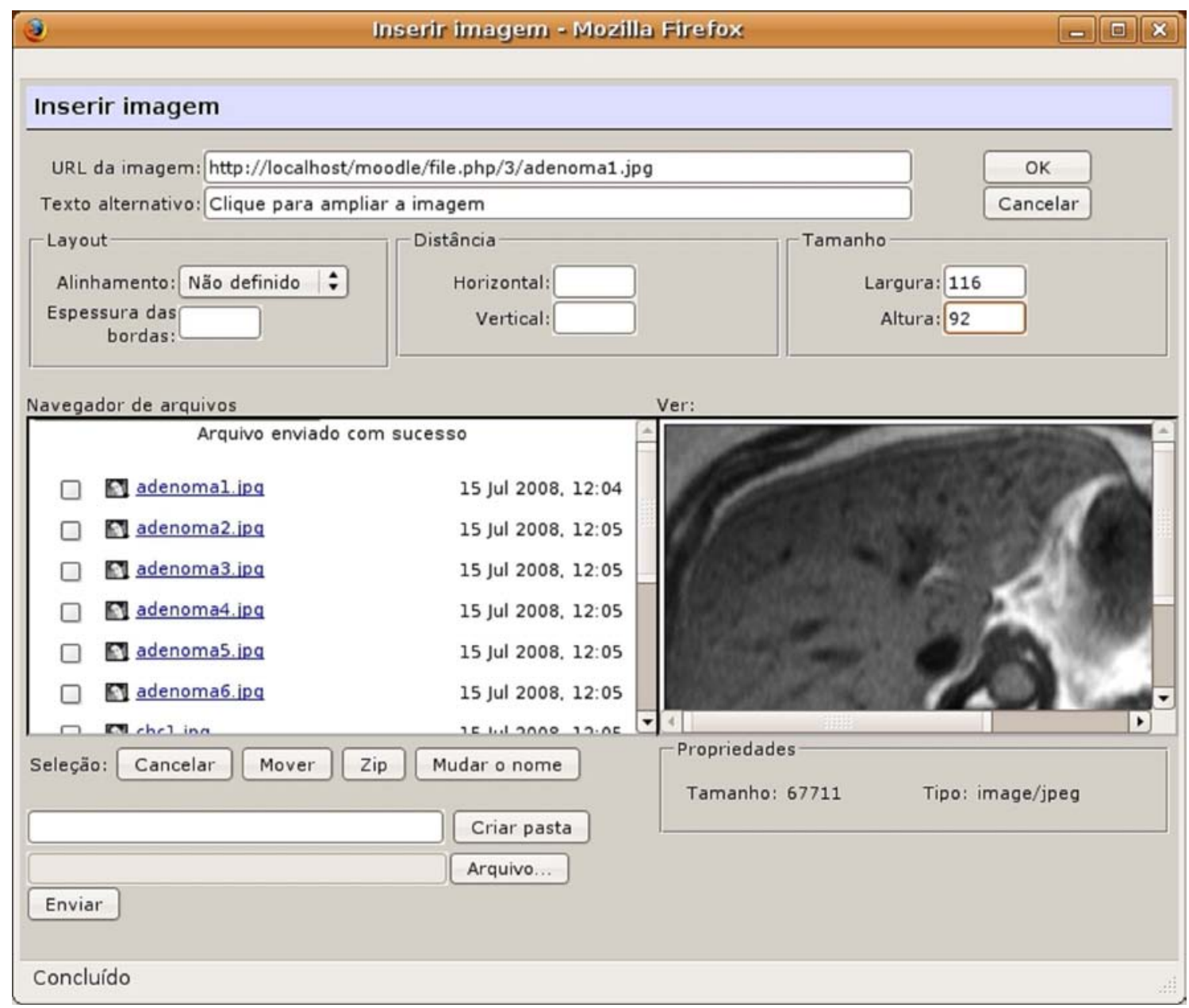

Figura 8. Ferramenta de inserção de imagens do Moodle.

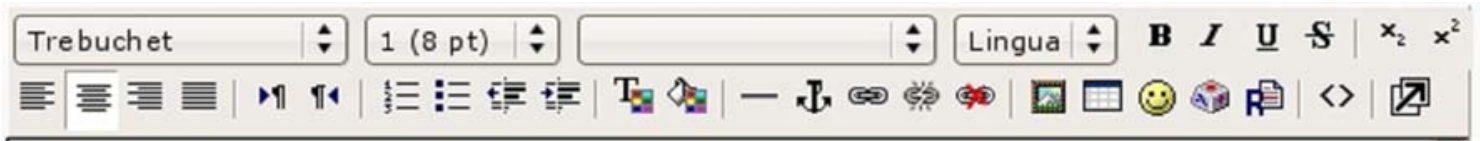

Analise as imagens a seguir e responda às questões:

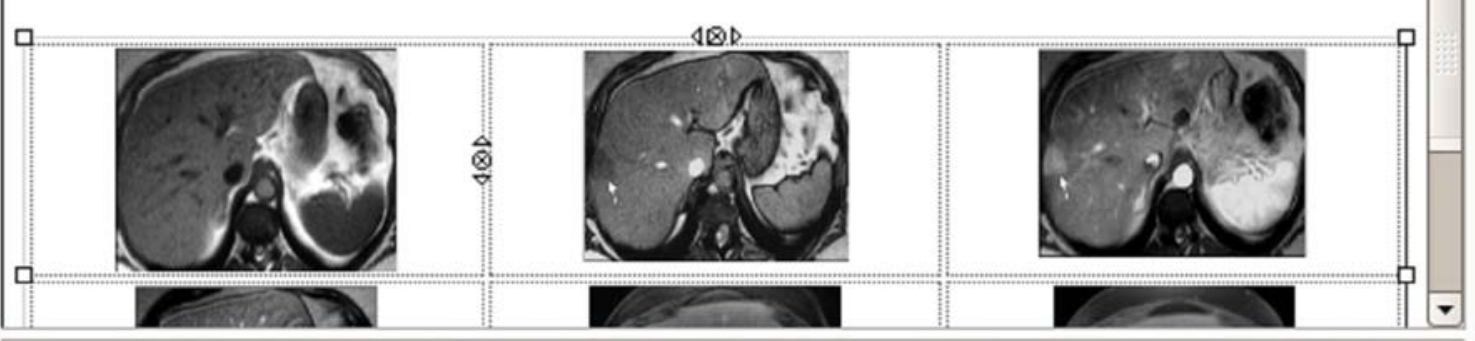

Caminho: body $*$ table $*$ tbody $* t r * t d$

Figura 9. Detalhe do editor WYSIWYG exibindo os thumbnails das imagens criados dentro das células de uma tabela. 
A visualização em thumbnails não permite que os alunos efetuem uma análise mais precisa das imagens. Conforme a proposta deste trabalho, as imagens em seu tamanho original devem ser exibidas dentro de janelas pop-up após um clique de mouse sobre o thumbnail correspondente, porém o Moodle não oferece nenhum recurso de interface para isso. Assim, foi necessário pensar uma solução paliativa para atingir esse propósito, através da utilização de comandos JavaScript ${ }^{27}$.

Criados todos os thumbnails, é preciso mudar o modo do editor WYSIWYG para TEXTO e inserir o código JavaScript em meio ao código HTML exibido. Na Figura 10 são exibidos o código resultante da criação de um dos thumbnails e o código JavaScript inserido posteriormente de forma manual. A função openpopup é implementada pelo próprio Moodle.

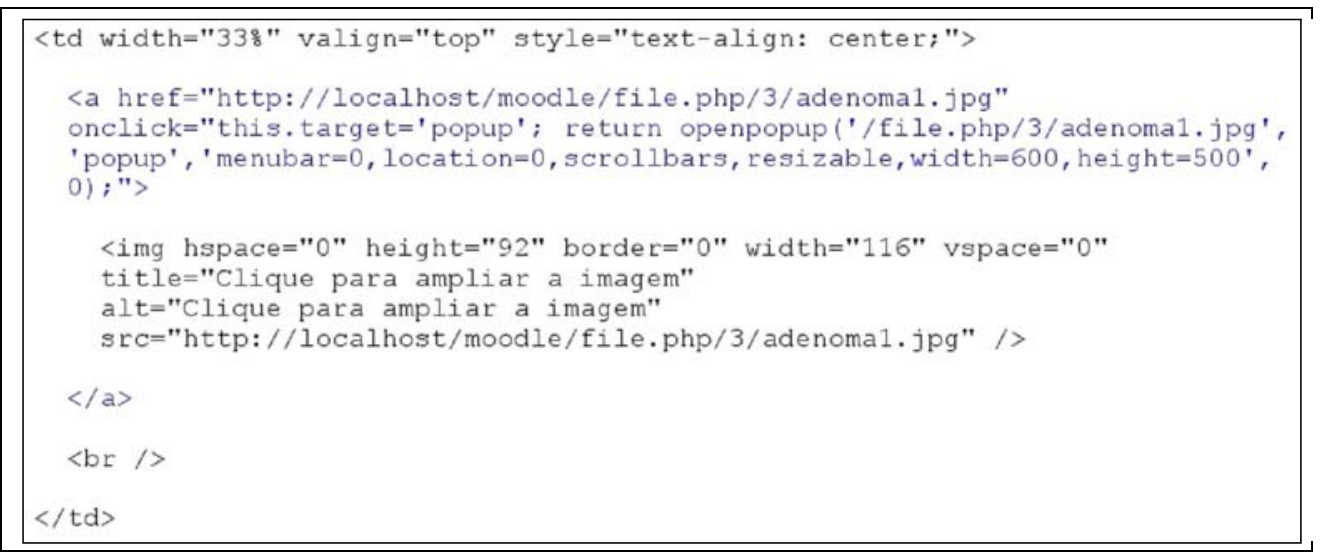

Figura 10. Código-fonte em JavaScript para exibir imagem em um thumbnail e abri-la em tamanho maior em janela pop-up após clique de mouse. $O$ trecho em azul foi inserido manualmente.

Com o Moodle foi possível criar questões de múltipla escolha de maneira fácil e ágil. O enunciado da questão é inserido em um editor WYSIWYG e um valor de relevância pode ser definido para a questão no campo "Nota". Podem ser cadastradas tantas alternativas quantas quiser e, para cada alternativa, pode ser definido um feedback diferente ao aluno. Para cada alternativa pode-se também definir um valor percentual que varia de -100 (cem negativo) a 100 (cem) definindo o quão correta ela é. Se o desejável é que apenas uma opção seja correta, basta definir o valor de $100 \%$ para a correta e o valor "Nenhum" para as demais. O sistema também permite a definição de feedbacks genéricos para qualquer questão que seja correta, qualquer questão que seja incorreta e qualquer questão que seja parcialmente correta.

27 Linguagem de programação criada e utilizada para o desenvolvimento de aplicações Web para serem executadas na máquina do cliente. 
Da mesma forma, as questões de verdadeiro/falso do Quiz foram criadas no Moodle de maneira simples. O enunciado é inserido com a ajuda do editor, o valor de relevância da questão é definido e a opção correta da questão (verdadeira ou falsa) é escolhida. Também é possível a inserção de feedbacks distintos para as duas opções.

Quando o aluno acessa um determinado Quiz, uma tela de apresentação é mostrada, contendo o nome do Quiz, um texto definido pelo professor e um botão para o aluno acessar o questionário. Quando o botão é clicado, uma janela de diálogo é aberta trazendo algumas informações sobre o funcionamento do Quiz. Um exemplo da tela e janela de diálogo é exibido na Figura 11.

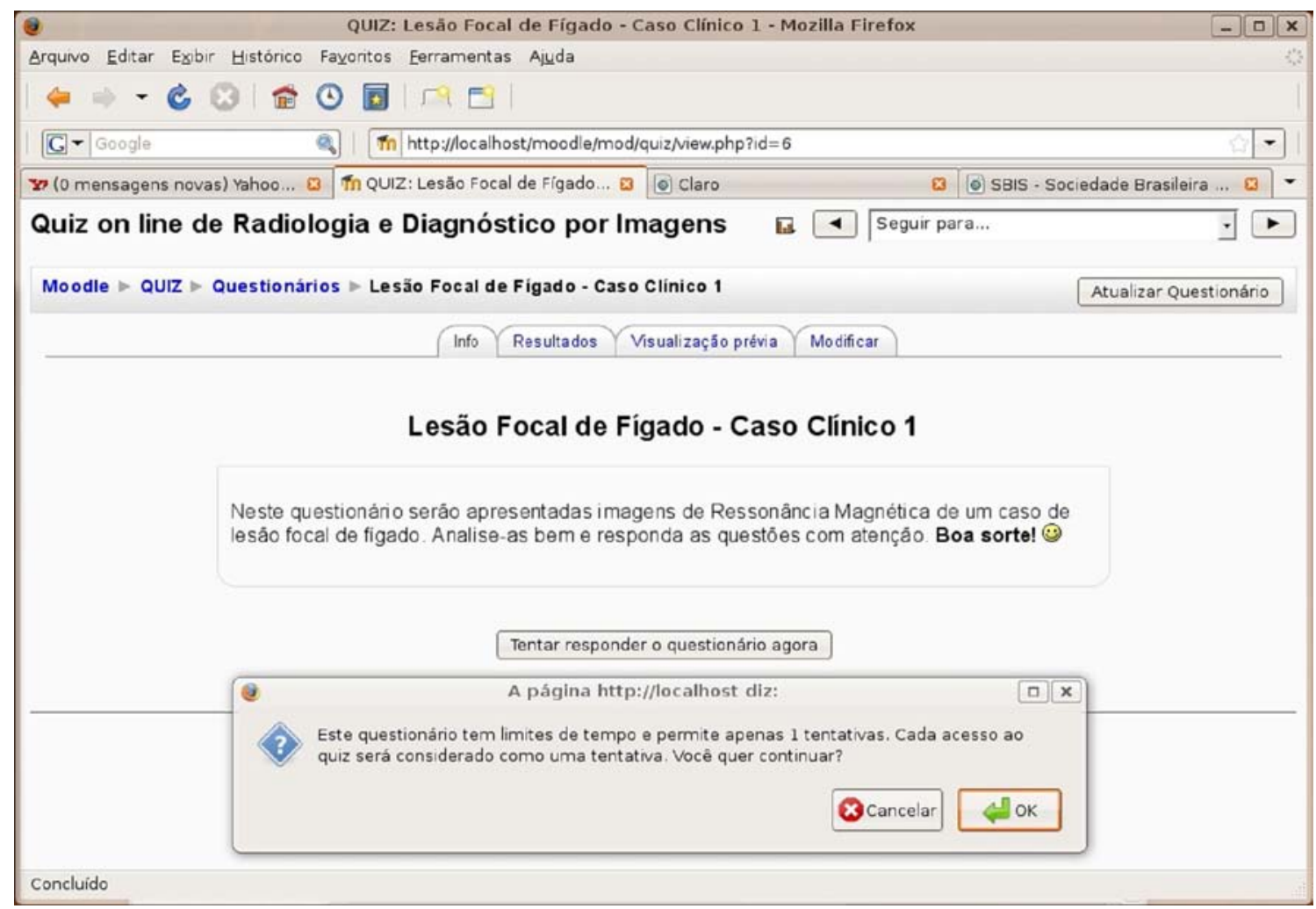

Figura 11. Tela de abertura do Quiz.

Ao clicar no botão "OK" da janela, o aluno é direcionado para a página de apresentação do Quiz, onde são exibidas as imagens que ele terá que avaliar e as questões que terá que responder. Logo abaixo de cada questão existe um "botão enviar", que permite que o aluno já obtenha o feedback de sua resposta tão logo tenha se decidido por ela. A Figura 12 apresenta um exemplo desta tela, com uma das imagens sendo exibida em um janela pop-up, uma questão respondida apresentando o feedback e uma questão a responder. 


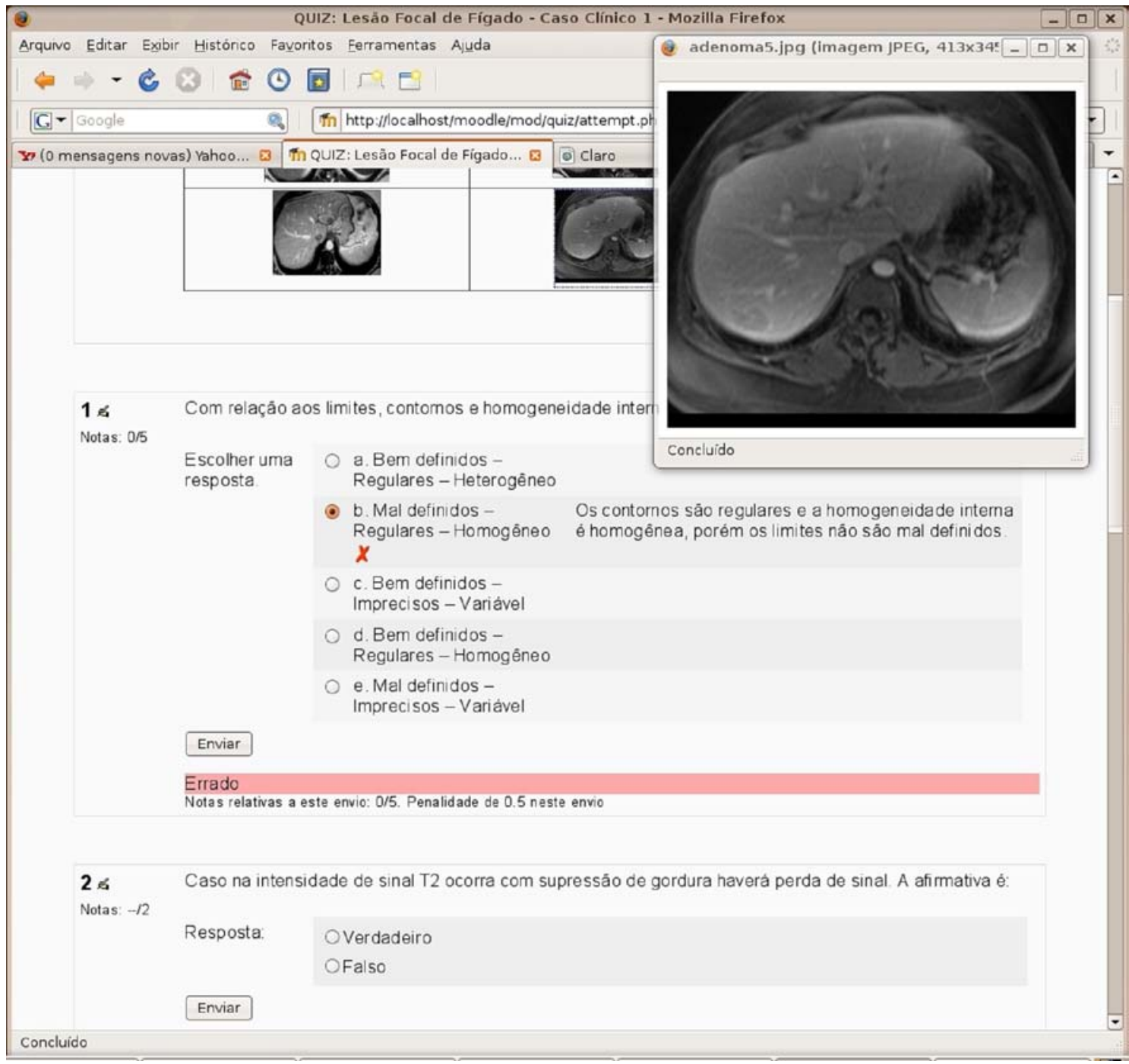

Figura 12. Proposta de "Caso do Dia” para Lesão Focal de Fígado; no destaque, uso de Pop-Up para exibição de imagem escolhida entre os Thumbnails.

No final da página há os botões "Salvar sem enviar", "Enviar página" e "Enviar tudo e terminar". Quando escolhe o último botão, o aluno é direcionado à página de revisão do caso (mostrada na Figura 13), onde pode verificar seu aproveitamento total no Quiz. 


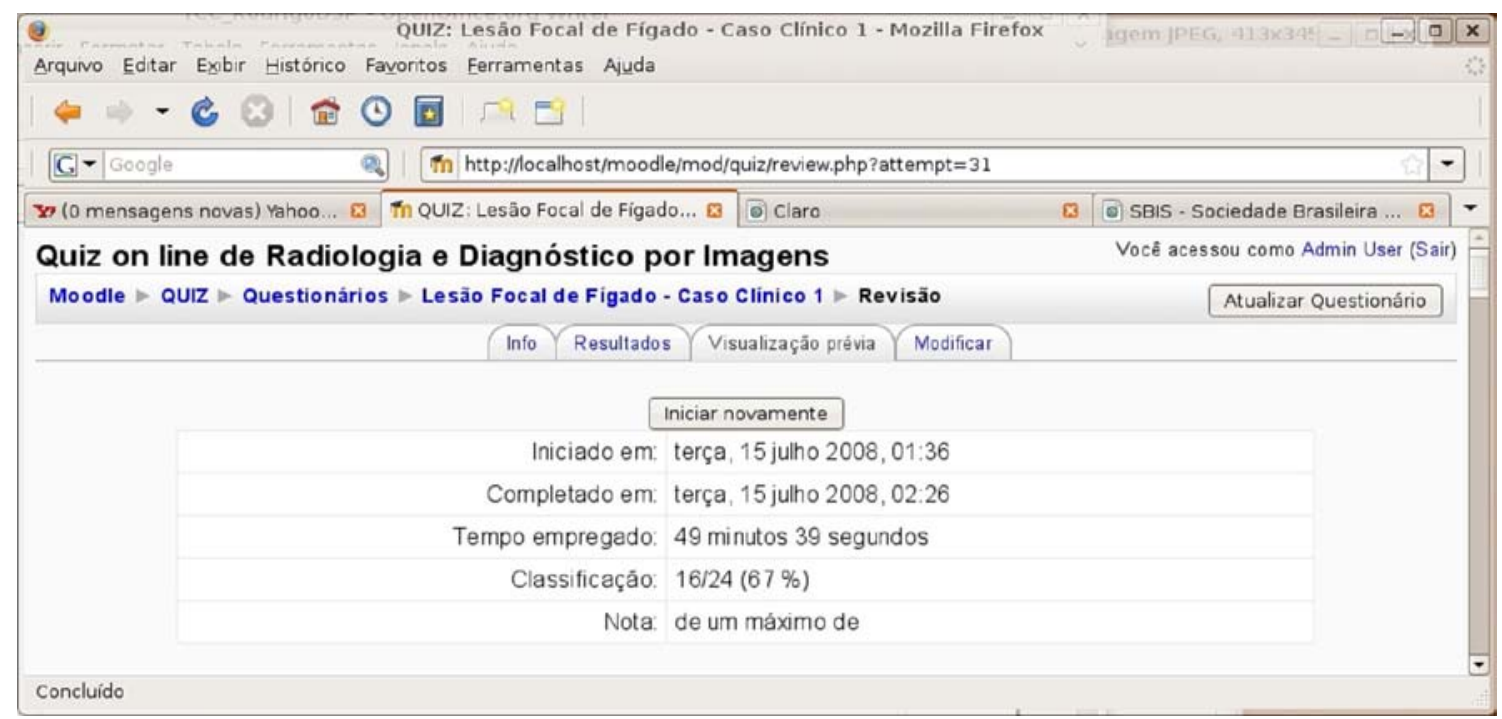

Figura 13. Tela de encerramento do Quiz.

\section{CONCLUSÃO}

Este trabalho apresentou uma proposta de criação de um Quiz On Line para treinamento em Radiologia e Diagnóstico por Imagem, utilizando o ambiente digital de aprendizagem Moodle. Esse ambiente permitiu a criação de questionários contendo imagens médicas e questões de múltipla escolha e verdadeiro/falso, de modo que as imagens podem ser visualizadas e avaliadas por alunos de medicina e médicos residentes.

O ambiente provê um sistema eficiente de feedback, que permite ao aluno obter informações de acordo com a resposta que escolher. Com ele, o aluno pode saber o porquê de sua resposta à questão estar correta ou incorreta tão logo escolha e confirme sua opção, o que propicia uma experiência mais efetiva de ensino-aprendizagem e facilita o processo de construção do conhecimento.

As ferramentas e funcionalidades do Moodle permitiram superar o serviço similar Case of the Day, oferecido pelo portal AuntMinnie.com, no que diz respeito às características funcionais dos questionários.

No entanto, o sistema ainda apresenta algumas limitações, como por exemplo o caso da inserção de imagens. Embora tenha sido possível obter o resultado desejado com a visualização das imagens em pop-ups, esse processo de criação não é intuitivo. Entretanto, por ter o Moodle a vantagem de ser ma ferramenta de distribuição livre e código-fonte 
aberto, esse e outros problemas podem ser contornados através de modificações no código do sistema de modo a propiciar customizações para atender melhor às expectativas do públicoalvo, os professores da área médica.

O próximo passo para o trabalho será submetê-lo a testes pelo corpo discente e docente da Faculdade de Medicina de Ribeirão Preto da Universidade de São Paulo, com vistas na aplicação dos recursos de tecnologia da informação para enriquecimento de práticas pedagógicas. Especialmente, quanto à implementação de uma interface mais amigável ao usuário, adequada à rotina dos profissionais envolvidos na produção de conteúdo para ensino e treinamento na área de Radiologia Médica e como recurso para avaliação de desempenho dos alunos.

\section{REFERÊNCIAS}

ALMEIDA, M. E. B. Educação a Distância na Internet: abordagens e contribuições dos ambientes digitais de aprendizagem. Educação e Pesquisa, São Paulo, v.29, n.2, p.327-340, 2003.

ÂNGELO, M. F.; SCHIABEL, H. Uma ferramenta para treinamento na avaliação de imagens mamográficas via internet. Radiologia Brasileira, São Paulo, v.35, n.3, p.259-265, 2002.

AUNTMINNIE.COM. Frequently Asked Questions: What is an Aunt Minnie? Disponível em: < http://www.auntminnie.com/index.asp?Sec=abt\&Sub=faq\&Pag=dis\&ItemId=50609> . Acesso em: 19 Jun 2008.

BASTOS, M. A. R.; GUIMARÃES, E. M. P. Educação a Distância na Área de Enfermagem: relato de caso. Revista Latino-Americana de Enfermagem, Ribeirão Preto, v.11, n.5, 2003.

CHRISTANTE, L.et al. O Papel do ensino a distância na educação médica continuada: uma análise crítica. Revista da Associação Médica Brasileira, São Paulo, v.49, n.3, 2003.

MOODLE.ORG. Sobre o Moodle. Disponível em: http://docs.moodle.org/pt br/Sobre o_Moodle . Acesso em: 13 Jun 2008.

ROCHA, H. V. O Ambiente TelEduc para Educação a Distância Baseada na Web: princípios, funcionalidades e perspectivas de desenvolvimento. In: MORAES, M. C. Educação a Distância: fundamentos e práticas. Campinas, SP: Unicamp/Nied, p.197-212, 2002. 
PIZZIO, R.; SILVA, M. M.; BELTRAN, J. E. R. WRAD: uma ferramenta para auxiliar no ensino da radiologia baseada em web. Revista da Faculdade de Zootecnia, Veterinária e Agronomia da PUC-RS, Uruguaiana, v.8, n.1, p.132-139, 2001.

SEMELKA, R. C.et al. MRI of focal lesions in normal and chronically diseased liver. In: HO, V. B.; KRANSDORF, M. J.; REINHOLD, C. (Org.). Body MRI: Categorical Course Syllabus. Leesburg, VA: American Roentgen Ray Society, p.11-38, 2006.

TIDIA-AE. Sobre o Projeto TIDIA-AE. Disponível: <http://tidiaae.incubadora.fapesp.br/portal/o-projeto>. Acesso em: 13 Jun 2008. 